\title{
Preference for Utilization of Skilled Birth Attendants (SBA) Services by Expectant Mothers in Mombasa County
}

\author{
Article by Johnson S. Manyiwa ${ }^{1}$, Oso W. Yuko ${ }^{2}$, Bob O. Opiyo ${ }^{3}$ \\ ${ }^{1}$ Public Health Department-Mombasa County \\ ${ }^{2}$ Amoud University \\ ${ }^{3}$ Technical University of Mombasa \\ E-mail: johnstoneshume@yahoo.com ${ }^{1}$
}

\begin{abstract}
Most obstetric complications could be prevented or managed if women had access to a skilled birth attendant SBAs; doctor, nurse, midwife during childbirth. Globally, almost $80 \%$ of live births occurred with the assistance of skilled health personnel in the period 2012-2017 up from $62 \%$ in the period 2000-2005. Improvements in the coverage of the proportion of births attended by SBAs and their provision of care may have contributed to declines in maternal mortality between 1990 and 2015.The study adopted a survey research design using semi-structured questionnaire and interview guide to collect data. That was collected from June to September, 2017. Interviews were conducted with 370 eligible expectant women residing in Mombasa County. Data was entered in the Epi Data database. Univariate statistics was explored to determine the frequency and percentage. Analysis was conducted in $R$ (version 3.4.3). All the 370 respondents had at one time visited the health facility to seek the services for pregnancy check-up. Factors like mother's checking their status and of the unborn (42.2\%), check-up/examination and treatment (17.6\%) were some of reasons cited by expectant mothers for visiting health facility, while factors such as nearness $(76.5 \%)$ and availability of essential services were some of reasons why expectant mothers visited a particular health facility. There is need to improve the quality of existing facility-based delivery services and strengthening linkages between the expectant mothers and the health facilities as to increase the deliveries.
\end{abstract}

Keywords: Delivery, Skilled Attendants, Traditional Attendants, Free Maternal Health, Health facilities, Mombasa County.

\section{Introduction}

Skilled birth attendant is important during pregnancy, at child birth as well as the post-natal (after delivery) period. According to WHO (1992), a skilled birth attendants (SBA) is an accredited health professional such as a midwife, physician, obstetrician, nurse, or other health care professional who provides basic and emergency health care services to women and their new-borns during pregnancy, childbirth and the postpartum period. The WHO (1992) adds that Birth attendants are trained to be present at ("attend") childbirth, whether the delivery takes place in a health care institution or at home, to recognize and respond appropriately to medical complication, and to implement interventions to help prevent them in the first place including through parental care.

According to a joint statement by WHO and UNICEF (2010), a skilled attendance at birth requires two key components viz: an SBA and an enabling environment that includes drugs and equipment, a functional referral system and enabling policies. Skilled birth attendance (SBA) is key to attaining MDG 4 and 5 as it's essential to save maternal and new-born lives. Therefore, ensuring that there are sufficient competent healthcare providers who can be considered SBAs is vitally important. Studies from different sites have demonstrated a positive correlation between the proportion of deliveries taking place with skilled birth attendance (SBA) and a reduction in maternal deaths (Utz et al., 2013).

The majority of maternal deaths are entirely preventable if the woman had an access to accredited health professional (SBAs) during childbirth so as to reduce the risk of complications becoming fatal and averts the risk of postpartum haemorrhage, which is viewed as the number one cause of maternal deaths universally (Taiwah, 2007). Globally, around four million new-borns die in the first week of life annually, while another 529,000 mothers die due to pregnancy-related causes. It was estimated 
that around $20-30 \%$ of the global neonatal mortality could be reduced by implementing skilled birth care services (WHO, 2012).

In a recent report released by WHO (2018), it was shown that almost $80 \%$ of live births occurred with the assistance of skilled health personnel in the period between 2012-2017, up from $62 \%$ in the 2000-2005 period with largest progress occurring in the last 10 years. However, coverage and the rate of progress have varied across regions. Central and Southern Asia has shown the greatest rate of progress from $40 \%$ coverage in the $2000-2005$ periods to $77 \%$ in the $2012-2017$ periods. Sub-Saharan Africa has also shown progress over the same period and by 2012-2017 over 50\% of births was attended by skilled health personnel (WHO, 2018). Improvements in the coverage of the proportion of births attended by skilled health personnel and their provision of care may have contributed to declines in maternal mortality between 1990 and 2015. However, the estimated coverage of births attended by skilled health personnel between 2012-2017 shows inequality between WHO regions as only $59 \%$ of the births in the sub-Saharan Africa Region, where maternal mortality is highest, are attended by skilled health personal whereas in the other WHO regions over $68 \%$ to $99 \%$ of all births are attended by skilled health personnel (WHO, 2018).

Several interventions have been laid down so as to improve maternal health and access to skilled birth attendants (SBA). For instance, Africa in her effort to accelerate improvement of maternal health launched its road map for accelerating the attainment of the Millennium Development Goals related to Maternal and New-born health in 2004, whose first objective was to provide skilled attendance during pregnancy, childbirth, and the postnatal period at all levels of the health care delivery system, using evidence-based standards of care (WHO, 2004). In addressing this issue as a matter of urgency, the Tanzanian government began implementation of One Plan, the National Road Map Strategic Plan to Accelerate Reduction of Maternal, Newborn and Child Deaths in Tanzania in 2008. The goal of One Plan was to reduce MMR by two-thirds by 2015, in accordance with national goals for meeting the Millennium Development Goals (MDGs). A key target for One Plan was to increase coverage of skilled birth attendance (SBA) from 46\% to 80\%, due to the Ministry of Health and Social Welfare's identification of low utilization of SBA and health facilities for childbirth as a major cause of maternal and neonatal morbidity and mortality in Tanzania (MoHSW, 2015). Following the implementation of One Plan, 90\% of all pregnant women managed to attend antenatal care at least once during their pregnancy, but only $43 \%$ of women managed to attend four times or more.

Kenya in her part to attain this target, set out targets in its first Health Sector Strategic and Investment Plan 2012-2018, aimed at improving skilled delivery from 44\% in 2012 (baseline) to $60 \%$ in 2015 (mid-term) and 65\% in 2018 (GoK, 2012). On her commitment to fulfil the Millennium Development Goals (MDG 5), on 1st June, 2013 the Kenya government rolled out free maternity services program. The program was meant to enable pregnant women to access free maternity services in all public health facilities. In a study conducted by Njuguna and colleagues (2017) on the impact of free delivery policy on utilization of maternal health services in county referral hospitals in Kenya they found out that the number of deliveries increased from 147,262 in 2013 to 186,688 in 2014 representing an increase of $26.8 \%$, thus signifying a positive impact of this program. On October 2016, the government through the Ministry of Health launched the expanded free maternal care programme dubbed "Linda Mama Boresha Jamii". "Linda Mama Boresha Jamii" is a great step forward towards improving access and quality of maternal, new born and child health care services in the country as well as attainment of health goals as outlined in Kenya's Vision 2030 and the Sustainable Development Goals 1, 3 and 10 related to poverty, good health/wellbeing and reduction of inequalities.

Despite all these overarching plans to improve maternal health indicators through improving attendance of skilled delivery, most of the expectant mothers still do not utilizes the services of skilled birth attendants. In Mombasa County, there is no existing data on contextual factors that lead to uptake of skilled delivery, hence the main objective of this study was determine factors that contribute to preference for utilization of skilled birth attendants by expectant mothers in Mombasa county, Kenya. The findings will be used to make recommendations on improving maternal health in Kenya and increasing the access and utilisation of skilled birth attendants. 


\section{Methods}

\section{Area of study}

The survey was conducted in Mombasa County, which is situated in the South Eastern part of the former Coast Province. Mombasa County is one of the 47 Counties of Kenya and it has a population of 939,370 (KNBS, 2009), with majority of her people living in urban areas. It consists of six subcounties and it is the smallest county in Kenya, covering an area of $229.7 \mathrm{~km}^{2}$ excluding $65 \mathrm{~km}^{2}$ of water mass. It borders Kilifi County to the North, Kwale County to the South, Taita Taveta to the West and the Indian Ocean to the East.

\section{Study population}

The study population comprised of 301,505 women of childbearing age (15-49) in Mombasa County (Government of Kenya, Projected 2016). The study included only expectant women who gave consent to participate in the study voluntarily and were resident of Mombasa County.

\section{Size of the study and sampling}

The number of study participants was calculated using the formula of Fishers et al (1998); $\mathrm{n}=$ $\mathrm{Z}^{2} \mathrm{pq} / \mathrm{d}^{2}$. Where $\mathrm{n}=$ sample size for a population; $\mathrm{Z}=\mathrm{z}$-value corresponding to a $95 \%$ level of significance $=1.96 ; \mathrm{p}=$ expected proportion of population of women in Mombasa County $=0.5 ; \mathrm{q}=$ $(1-p)=(1-0.5)=0.5 ;$ and $d=$ absolute precision, set at $5 \%$.

Therefore,

$$
\frac{1.96^{2} * 0.5 * 0.5}{0.05^{2}}=384 \text { pregnant women }
$$

Stratified random sampling and simple random sampling techniques was used to select the individual members of the sample. Stratified sampling technique was used to determine the proportion of women in each sub county to be included in the sample. Six strata corresponding to the six subcounties (Table 1) were identified. Simple random was used to select the individual members of each stratum for the sample.

Table 1. Stratified Sampling

\begin{tabular}{|l|l|l|}
\hline Sub-County & Approximate & Number \\
\hline Kisauni & $48680 / 301,505 \times 384$ & 62 \\
\hline Mvita & $73020 / 301,505 \times 384$ & 93 \\
\hline Nyali & $51821 / 301,505 \times 384$ & 66 \\
\hline Likoni & $45540 / 301,505 \times 384$ & 58 \\
\hline Jomvu & $41100 / 301,505 \times 384$ & 52 \\
\hline Changamwe & $41614 / 301,505 \times 384$ & 53 \\
\hline Total & & $\mathbf{3 8 4}$ \\
\hline
\end{tabular}

\section{Data collection}

The data was collected from June, 2017 to September, 2017. Data were collected using a semi structured interviewer-administered questionnaire. Trained enumerators were responsible for collecting the data. The survey was in English; however, the enumerators were capable of translating questions into Kiswahili and the local language, when necessary.

\section{Data management}

The principle researcher entered the data in EpiData database, and then exported to $\mathrm{R}$ (Version 3.4.3) for analysis. The outcome variable in this study was the place of delivery. The SBAs include doctor, nurse, midwife, and auxiliary nurse/midwife (Lincetto et al.,2010). Our outcome of interest was the factors that contribute to the utilization of skilled birth attendants. Basic descriptive statistics was used to determine the frequency and percentage of the various factors observed in this study. Chi square test was used to test the association between categorical variables where a $\mathrm{P}$ value of $<0.05$ was considered significant. The results were presented in tables. 
DOI: $10.21522 / \mathrm{TIJPH} .2013 .06 .03$. Art001

ISSN: $2520-3134$

\section{Ethical approval}

Ethical approval was obtained from the Mombasa County Research Ethical Review Board. The respondents were served with and introductory letter from the researcher that explained the purpose of the study and sought their permission to participate in the study. The study protected the privacy of the respondents and the confidentiality of the information provided by the respondents. Any information collected was not passed to third parties in any form whatsoever without express permission of the source.

\section{Results and discussion}

A total of 370 women were recruited for the study out of a target of 384 respondents representing $96.4 \%$ response rate. $275(74.3 \%)$ women who were recruited for this study were assisted by a skilled birth attendant at last delivery compared to $95(25.7 \%)$ who were not.

\section{Socio demographic characteristics of the expectant mothers in the study}

As shown in Table 2 regarding to the socio demographics of the respondents, the study established that, majority of the respondents $133(35.9 \%)$ and $131(35.4 \%)$ had primary education and no formal education respectively while $89(24.1 \%)$ and $17(4.6 \%)$ had secondary and tertiary educations respectively. In studies conducted by Fisher and colleagues (1998), Mwewa and Michelo (2010) reported that educated women tend to give birth to few children and deliver at a health facility compared to women with little or no education. $71(19.2 \%)$ of the study participants were not involved any relationship, $9(2.4 \%)$ had lost their spouse through death while more than three-quarters $(78.4 \%)$ were married; slightly more than half $(56.2 \%)$ were married under Traditional beliefs, while $28.1 \%$ and $15.7 \%$ were married under Christian and Islamic faiths respectively. Ahmed and AbdelRahman (2008) reported out that there is strong belief in religious restrictions, conservativeness and strict rules of maintaining the Islamic principle of purdah that actually limit the mobility of women significantly. In fact, there are cases where women believe that it is a sin to deliver outside of home because it violates purdah (Ahmed \& Abdel-Rahman, 2008). Most of the respondents had delivered 2 or 3 children, each constituting to $29.2 \%$ of the respondents. Moreover, majority (80\%) of the respondents reported that their delivered children were alive.

Table 2. Sociodemographic data of the respondents

\begin{tabular}{|l|l|l|}
\hline Variables & $\begin{array}{l}\text { No of } \\
\text { Responden } \\
\text { ts (n) }\end{array}$ & Proportion (\%) \\
\hline $\begin{array}{l}\text { a). Education background } \\
\text { (n=370) }\end{array}$ & 131 & 35.4 \\
$\begin{array}{l}\text { No Education } \\
\text { Primary }\end{array}$ & 133 & 35.9 \\
Secondary & 89 & 24.1 \\
Tertiary & 17 & 4.6 \\
\hline b). Marital status (n=370) & & \\
Single & 71 & 19.2 \\
Married & 290 & 78.4 \\
Widow & 9 & 2.4 \\
\hline $\begin{array}{l}\text { c). Nature of married } \\
\text { (n=299) }\end{array}$ & 168 & 56.2 \\
$\begin{array}{l}\text { Traditional } \\
\text { Christian } \\
\text { Muslim }\end{array}$ & 84 & 28.1 \\
\hline
\end{tabular}




\begin{tabular}{|l|l|l|}
\hline d). Number of children & & \\
delivered $(\mathbf{n = 3 7 0})$ & 46 & 12.4 \\
1 & 108 & 29.2 \\
2 & 108 & 29.2 \\
3 & 54 & 14.6 \\
4 & 27 & 7.3 \\
5 & 18 & 4.9 \\
6 & 8 & 2.2 \\
7 & 1 & 0.2 \\
8 & & \\
\hline e). All children delivered & & \\
are alive (n=370) & 296 & 80 \\
Yes & 74 & 20 \\
No & & \\
\hline
\end{tabular}

\section{Respondents' knowledge on Skilled Birth Attendant (SBAs) and their services}

As presented in Table 3, it was noted that all the respondents' recruited for the study had at one time sought the services of Skilled Birth Attendant (SBAs) for pregnancy check-up. More than a quarter [118(31.9\%)] of the respondents' sought these services at midway of their pregnancy while a quarter [93(25\%)] of the respondents sought out these services during the early stages of their pregnancy, 58(15.7\%) sought the services of Skilled Birth Attendant (SBAs) at the fifth month of their pregnancy, 48(13\%) sought the services of Skilled Birth Attendant (SBAs) during the late stages of their pregnancy. Moreover, 21(5.7\%) of the respondents only sought the services of Skilled Birth Attendant (SBAs) when they were sick while 16(4.3\%), 11(3\%) and 5(1.4\%) sought the services of Skilled Birth Attendant (SBAs) at sixth, fourth and third months of their pregnancy respectively.

Furthermore, the respondents reported that the main reasons why they visited the health facility was to check on they're and that of the unborn status 156(42.2\%). 65(17.6\%) of the respondents visited the health facility for medication, while $48(13 \%)$ visited the health facility for both check-up and medication. It was also observed that, 36(9.7\%) of the participants cited that they visited the health facilities during the course of their pregnancy so as to avoid rejection from health staffs (nurses) when their pregnancy developed complications. 35(9.5\%) of the respondents visited the health facility for check-up and treatment, 16(4.3\%) visited the health facility for treatment and medication. Moreover, $11(3 \%)$ visited the health facility so as to get clinic cards while $3(0.8 \%)$ of the respondents stated that they visited the health facility for check-up, treatment and medication.

The predominant type of health facility utilized by the majority of the respondents was the dispensary $262(70.8 \%)$ while $88(23.8 \%$ ) and $20(5.4 \%)$ of the respondents obtained their services from health centre and hospital respectively. Majority [283(76.5\%)] cited that the reason why they frequented a particular type of health facility was due to its closeness to them. 52(14.1\%) of the respondents cited that they visited a particular type of health facility as it provided all services including maternal services, while $12(3.2 \%)$ of the respondents stated the reason why they attended a particular health facility was because it provided all services and also the maternal services were free. Moreover, $10(2.7 \%)$ of the respondents stated that the health facility they visited provided all the services while $6(1.6 \%), 6(1.6 \%)$ and $1(0.3 \%)$ choose a particular health facility since it offers free maternal services, nearer and offers all services and also it was nearer and offers free maternal services respectively.

Of all the respondents interviewed, 353(95.4\%) were satisfied with the services they received from the health facility while $17(4.6 \%)$ were unsatisfied with the services they received in the health facilities. When the respondents were asked to rate the services they received at the health facility, majority [353(95.4\%)] indicated that they had received good services, while 7(1.9\%) reported receiving poor services since the facility lacked nutritional advice, further, $6(1.6 \%)$ and $4(1.1 \%)$ of the respondents' also cited receiving poor services since they took a lot of time at the facility and were also harassed by the health staffs respectively. It was also observed that slightly three-quarters [196(71.3\%)] of the respondents had delivered one child in the presence of skilled birth attendants, 
DOI: $10.21522 /$ TIJPH.2013.06.03.Art001

ISSN: $2520-3134$

55(20\%) had delivered two children in the presence of skilled birth attendants. 13(4.7\%), 5(1.8\%), $3(1.1 \%), 2(0.7 \%)$ and $1(0.4 \%)$ had delivered three, six, seven, five and four children respectively in the presence of skilled birth attendants.

Table 3. Knowledge concerning skilled birth attendant (SBAs) and their services

\begin{tabular}{|c|c|c|}
\hline Variable & $\begin{array}{l}\text { No of Respondents } \\
\text { (n) }\end{array}$ & Proportion (\%) \\
\hline $\begin{array}{l}\text { a). Went at one time to } \\
\text { Health facility (SBAs) for } \\
\text { Pregnancy check-up } \\
\text { (n=370) } \\
\text { Yes } \\
\text { No }\end{array}$ & $\begin{array}{l}370 \\
0\end{array}$ & $\begin{array}{l}100 \\
0\end{array}$ \\
\hline $\begin{array}{l}\text { b). Time when visited } \\
\text { Health facility (SBAs) for } \\
\text { Pregnancy check-up } \\
\text { (n=370) } \\
\text { During Early Stages of } \\
\text { Pregnancy } \\
\text { At } 3 \text { months } \\
\text { At } 4 \text { months } \\
\text { At the Middle of Pregnancy } \\
\text { At } 5 \text { months } \\
\text { At } 6 \text { months } \\
\text { During Late Stages of } \\
\text { Pregnancy } \\
\text { When sick }\end{array}$ & $\begin{array}{l}93 \\
5 \\
11 \\
118 \\
58 \\
16 \\
48 \\
21\end{array}$ & $\begin{array}{l}(25) \\
(1.4) \\
(3) \\
(31.9) \\
(15.7) \\
(4.3) \\
(13) \\
(5.7)\end{array}$ \\
\hline $\begin{array}{l}\text { c). Reason for visiting } \\
\text { Health facility (n=370) } \\
\text { To avoid rejection by } \\
\text { health staffs (nurses) if } \\
\text { pregnancy developed } \\
\text { complications } \\
\text { To check mother's and } \\
\text { unborn status } \\
\text { To get clinic card } \\
\text { Check-up/examination and } \\
\text { treatment } \\
\text { Medication } \\
\text { Check-up/examination and } \\
\text { medication } \\
\text { Medication and treatment } \\
\text { Check-up, treatment and } \\
\text { medication }\end{array}$ & $\begin{array}{l}36 \\
156 \\
11 \\
35 \\
65 \\
48 \\
16 \\
3\end{array}$ & $\begin{array}{l}(9.7) \\
(42.2) \\
(3) \\
(9.5) \\
(17.6) \\
(13) \\
(4.3) \\
(0.8)\end{array}$ \\
\hline $\begin{array}{l}\text { d). Type of health facility } \\
\text { visited }(\mathbf{n}=\mathbf{3 7 0}) \\
\text { Dispensary } \\
\text { Health Centre } \\
\text { Hospital } \\
\end{array}$ & $\begin{array}{l}262 \\
88 \\
20\end{array}$ & $\begin{array}{l}(70.8) \\
(23.8) \\
(5.4)\end{array}$ \\
\hline
\end{tabular}




\begin{tabular}{|c|c|c|}
\hline $\begin{array}{l}\text { e). Reason for visiting a } \\
\text { particular type of health } \\
\text { facility (n=370) } \\
\text { It's nearer } \\
\text { Has all services including } \\
\text { maternal services? } \\
\text { Has all services and } \\
\text { maternal services are also } \\
\text { free } \\
\text { Offers good services } \\
\text { Offer free maternal services } \\
\text { Nearer and offer all } \\
\text { services } \\
\text { Nearer and also offer free } \\
\text { maternal services }\end{array}$ & $\begin{array}{l}283 \\
52 \\
12 \\
10 \\
6 \\
6 \\
1\end{array}$ & $\begin{array}{l}(76.5) \\
(14.1) \\
(3.2) \\
(2.7) \\
(1.6) \\
(1.6) \\
(0.3)\end{array}$ \\
\hline $\begin{array}{l}\text { f). Satisfied by the } \\
\text { services offered by the } \\
\text { health facility visited } \\
\text { (n=370) } \\
\text { Yes } \\
\text { No }\end{array}$ & $\begin{array}{l}353 \\
17\end{array}$ & $\begin{array}{l}(95.4) \\
(4.6)\end{array}$ \\
\hline $\begin{array}{l}\text { e). Rating of the services } \\
\text { offered by the health } \\
\text { facility visited (n=370) } \\
\text { Good } \\
\text { Poor (didn't receive } \\
\text { nutritional advice) } \\
\text { Poor (took a lot of time) } \\
\text { Poor (harassed by health } \\
\text { staffs) }\end{array}$ & $\begin{array}{l}353 \\
7 \\
6 \\
4\end{array}$ & $\begin{array}{l}(95.4) \\
(1.9) \\
(1.6) \\
(1.1)\end{array}$ \\
\hline $\begin{array}{l}\text { f). Have delivered a } \\
\text { baby at one time in the } \\
\text { presence of skilled birth } \\
\text { attendant }(n=370) \\
\text { Yes } \\
\text { No }\end{array}$ & $95^{275}$ & $\begin{array}{c}(74.3) \\
(25.7)\end{array}$ \\
\hline $\begin{array}{l}\text { g). Number of times } \\
\text { delivered a baby in the } \\
\text { presence of skilled birth } \\
\text { attendant (n=275) } \\
1 \\
2 \\
3 \\
4 \\
5 \\
6 \\
7\end{array}$ & $\begin{array}{l}196 \\
55 \\
13 \\
1 \\
2 \\
5 \\
3\end{array}$ & $\begin{array}{l}(71.3) \\
(20) \\
(4.7) \\
(0.4) \\
(0.7) \\
(1.8) \\
(1.1)\end{array}$ \\
\hline
\end{tabular}

\section{Respondents' preference for the utilization of skilled birth attendant services}

As shown in Table 4, slightly more than a quarter (31.3\%) of the respondents indicated that they were motivated to deliver in the presences of skilled birth attendant by the fear of developing complication with their first pregnancy. Moreover, 63(22.9\%) of the respondents indicated that their nearness to skilled birth attendants (SBAs) motivated them to seek their services. Moore and 
DOI: $10.21522 / \mathrm{TIJPH} .2013 .06 .03$. Art001

ISSN: $2520-3134$

colleagues (2002), in their study identified one of the barriers to use of skilled attendance as distance, physical proximity of facility or care source. The ,preferred care source is always the closest care source. This was emphasized by an In-depth interviewee who reported that distance to the hospital was one of the factors that influenced the selection of delivery assistance making most women to seek assistance from the nearest person. 27(9.8\%) of the expectant mothers indicated that their husband motivated them to seek services of the skilled birth attendants (SBAs). Martin and colleagues (2010) noted that to improve maternal services utilization, the involvement of male partners in mobilizing resources for health facility birth must be a focus for intervention. Moreover, 24(8.7\%) of the expectant mothers indicated that they were motivated by other mothers so as to seek services of the skilled birth attendants (SBAs) while 19(6.9\%) and 19(6.9\%) of the study participants reported that personal decision and a combination of both personal and husband's decision influenced their choice to seek services of the skilled birth attendants (SBAs) respectively. Furthermore, 13(4.7\%), 9(3.3) and $7(2.5 \%)$ of the respondents indicated that their source of motivation was from the other family members, a combination of both personal and other family members decision and a combination of both community members and nearness to skilled birth attendant respectively. 6(2.2\%) of the respondents further reported that, the complications they had experienced with their previous pregnancy motivated them to seek skilled birth attendants (SBAs). 2(0.7\%) of the participants indicated that the information they received from the chiefs "barazas" and other mothers motivated them to seek services of skilled birth attendants (SBAs).

Almost all of the respondents' (97.8\%) recruited for this study revealed that they would encourage other pregnant women to seek the services of skilled birth attendant while only $6(2.2 \%)$ of the respondents indicated that they won't encourage other pregnant women to seek the services of skilled birth attendant. Of those who indicated that they would encourage their other colleagues to seek the services of skilled birth attendant, 133(48.4\%) of them felt that delivering in the presences of skilled birth attendant was safe and healthy. $100(36.4 \%)$ of the respondents indicated that they would encourage their colleagues to seek services of skilled birth attendants in order for them to receive wide range of good maternal services while 20(7.2\%) of the respondents suggested that they would encourage their colleagues to seek the services of skilled birth attendants so as to get served by expert. Further, 7(2.5\%) and 6(2.2\%) of the respondents reported that they would encourage their colleagues to seek the services of skilled birth attendants so as to avoid being exploited by Traditional Birth Attendants (TBAs) and to be received in the hospital later on respectively. However, 9(3.3\%) indicated that they would not encourage their colleagues to seek the services of skilled birth attendants since these services were being paid for. 
Table 4. Respondents' preference for the use of skilled birth attendant services

\begin{tabular}{|c|c|c|}
\hline Characteristics & $\begin{array}{l}\text { No of Respondents } \\
\text { (n) }\end{array}$ & $\begin{array}{l}\text { Proportion } \\
(\%)\end{array}$ \\
\hline $\begin{array}{l}\text { i). Whom/what motivated delivery of the baby } \\
\text { in the presence of skilled birth } \\
\text { attendant(n=275) } \\
\text { It was the first pregnancy and feared developing } \\
\text { complications } \\
\text { Nearness to skilled birth attendant } \\
\text { Husband } \\
\text { Other mothers } \\
\text { Personal decision } \\
\text { Personal and husband's decision } \\
\text { Other family members decision } \\
\text { Personal and other family members } \\
\text { decision } \\
\text { Community members and nearness to skilled } \\
\text { birth attendant } \\
\text { Previous pregnancy had complications } \\
\text { Information from chiefs "barazas" and other } \\
\text { mothers }\end{array}$ & $\begin{array}{l}86 \\
63 \\
27 \\
24 \\
19 \\
19 \\
13 \\
9 \\
7 \\
6 \\
2\end{array}$ & $\begin{array}{l}(31.3) \\
(22.9) \\
(9.8) \\
(8.7) \\
(6.9) \\
(6.9) \\
(4.7) \\
(3.3) \\
(2.5) \\
(2.2) \\
(0.7)\end{array}$ \\
\hline $\begin{array}{l}\text { ii). Encourage other pregnant women to } \\
\text { deliver in presence of skilled birth attendant } \\
(\mathbf{n}=\mathbf{2 7 5}) \\
\text { Yes } \\
\text { No }\end{array}$ & $\begin{array}{l}269 \\
6\end{array}$ & $\begin{array}{l}(97.8) \\
(2.2)\end{array}$ \\
\hline $\begin{array}{l}\text { iii). Reasons for encouraging other pregnant } \\
\text { women to deliver or not to deliver in the } \\
\text { presence of skilled birth attendant }(\mathbf{n}=\mathbf{2 7 5}) \\
\text { To receive wide range of good maternal services } \\
\text { To get safe and healthy delivery } \\
\text { To get delivered by experts and professionals } \\
\text { To avoid being exploit by TBAs } \\
\text { To be able to be received in the hospital later } \\
\text { SBAs services are paid for }\end{array}$ & $\begin{array}{l}100 \\
133 \\
20 \\
7 \\
6 \\
9\end{array}$ & $\begin{array}{l}(36.4) \\
(48.4) \\
(7.2) \\
(2.5) \\
(2.2) \\
(3.3)\end{array}$ \\
\hline
\end{tabular}

\section{Reasons for not utilizing the free maternity services offered by the government}

As shown in Table 5, regarding non-compliance to utilization of free maternity services introduced by the government on $1^{\text {st }}$ June 2013 , it was observed that the reason why majority of the pregnant women were not turning up for these free maternity services was because they felt that the health facilities were far from them, receiving harassment from health staffs (nurses) and paying for unavailable items in most of the facilities $110(40 \%)$.

Other combination of reasons given by these pregnant women for failing to seek free maternity services were; due to poverty, illiteracy and culture/tradition 74(26.9\%), lack of equipment and staffs $22(8 \%)$, insecurity when labour pain occurs at night 14(5.1\%), strict culture, health facilities being far, harassment by nurses $14(5.1 \%)$, hate being looked by many people when giving birth $11(4 \%)$, not all facilities conducts delivery $7(2.5 \%)$ and some men forbid delivery at the health facility $6(2.2 \%)$.

Shiferaw and colleagues (2013) in their study reported that most women delivered at home because the labor began suddenly and the health facility was far. Similarly, Titaley and colleagues (2010) and Vieira and colleagues (2012) both reported significance of culture and deliveries conducted at home. Titaley and colleagues (2010) indicated that, in some cultures, there are certain rituals that follow delivery whereby the home provides a good environment. Thaddeus and Maine (1994) stated that 
most pregnant women are not able to access transport services when they develop labor mostly due to the poor road network and infrastructure especially in rural and poor urban regions in Africa. Similarly, Lunan and colleagues 2009) reported that availability of affordable transport and the condition of the roads influences the decision to attend a service at a health facility. Within rural Mombasa County, health facilities are sparsely distributed with very poor road network and erratic public transport system. Most of the women could have developed labor at night when the public means of transport is not available. Interventions such as "waiting homes" near health facilities to accommodate the expectant mothers residing far from the nearest health facilities days before delivery day can be helpful in such scenarios.

Table 5: Reasons for not utilizing the free maternity services offered by the government

\begin{tabular}{|l|l|l|}
\hline $\begin{array}{l}\text { Reasons why most pregnant women do no go for free } \\
\text { maternity offered by the government (n=275) }\end{array}$ & 110 & $(40)$ \\
Health facilities far, harassment by health staffs (nurses), & 74 & $(26.9)$ \\
payment for unavailable items & 22 & $(8)$ \\
Poverty, illiteracy and culture/tradition & 14 & $(5.1)$ \\
Lack of equipment and lack staffs & 14 & $(5.1)$ \\
Insecurity when labour pain occurs at night & 11 & $(4)$ \\
Strict culture, health facilities far, harassment by nurses & 7 & $(2.5)$ \\
Hate being looked by many people when giving birth & 6 & $(2.2)$ \\
Not all facilities conduct delivery & 6 & $(2.2)$ \\
Some men forbid it & 5 & $(1.8)$ \\
Illiteracy & 4 & $(1.5)$ \\
No idea & 1 & $(0.4)$ \\
Presence of male nurses & 1 & $(0.4)$ \\
Low education level, culture and health facility are far & & \\
Lack of good transport means & & \\
\hline
\end{tabular}
Association between respondents' knowledge of skilled birth attendant and the place of
delivery

As shown in table 6, respondents who reported to had at one time gone to health facility and sought services of skilled birth attendants (SBAs) for pregnancy check-up had a higher proportion (74.3\%) of delivering at home/outside hospital, though the difference was insignificant.

Delivering a baby at home/outside hospital was higher among expectant mothers who visited health facilities to sought out services of skilled birth attendants (SBAs) during late stages of their pregnancy (89.6\%) and among those who had visited the health facilities for skilled birth attendants (SBAs) services only when they were sick $(85.7 \%)$. This difference in proportion was statistically significant (chi=64.61, $\left.\mathrm{p}=1.80 \mathrm{e}^{-11}\right)$.

Expectant mothers who had visited health facilities so as to obtain clinic card and for check-up, treatment and medication had higher proportion (100\%) of delivering a baby at home/outside hospital among other reasons given by these expectants mothers for visiting the health facilities. This difference in proportion too, was significant ( $\mathrm{chi}=29.03, \mathrm{p}=0.0001$ ).

Respondents who sought maternal services at the dispensary had highest proportion of home/outside hospital delivery (92.7\%) than other type of health facility and the differences in proportion was significant ( $\mathrm{chi}=167.46, \mathrm{p}=<2.2 \mathrm{e}^{-16}$ ).

Assessment on the reason for visiting a particular type of health facility showed that those who responded that the particular health facility they visited provided good services had a higher proportion (90\%) of delivering their babies at home/outside hospital. This difference in proportion too, was significant $\left(\mathrm{chi}=151.85, \mathrm{p}=<2.2 \mathrm{e}^{-16}\right)$.

Similarly, the respondents who stated that they were not satisfied by the services offered by the health facility they visited had a higher proportion (94.1\%) of home/outside hospital delivery as compared to the ones who were satisfied with the services offered by the health facility even though the difference was not significant $(\mathrm{chi}=2.65, \mathrm{p}=0.1034)$. Further logistic regression analysis showed 
that those who were not satisfied by the services offered by the health facility they visited had an increase odd of delivering at home/outside hospital by 0.17 ( $\mathrm{OR}=0.17$ [95\% CI=0.02-1.32]) as compared to those who were satisfied with the services offered by the health facility.

With regards to rating of a particular health facility visited, those who responded that the health facility they visited offered poor services since it lacked nutritional services and they were also harassing patients, had a high proportion (100\%) of home/outside hospital delivery. This difference in proportion observed, was also not significant (chi=4.22, $\mathrm{p}=0.2383$ ).

The study participants who responded that they never delivered a baby in the presences of skilled birth attendants (SBAs), had a higher proportion 95(100\%) of home/outside hospital delivery as compared to those who had delivered at one time in the presence of skilled birth attendants (SBAs). This difference in proportion was significant $\left(\mathrm{chi}=42.36, \mathrm{p}=7.58 \mathrm{e}^{-11}\right)$.

Furthermore, it was observed that the study participants who had previously delivered only once in the health facilities in the presences of skilled birth attendants (SBAs) had a higher proportion $157(80.1 \%)$ of home/outside hospital delivery as compared to those who had delivered more than once. This difference in proportion observed, was also significant $\left(\mathrm{chi}=74.38, \mathrm{p}=5.14 \mathrm{e}^{-14}\right.$ ). Further logistic regression analysis showed that those who had delivered two children in the presences of skilled birth attendants (SBAs) had the odds of delivering at home/outside hospital increased by 6.04 $(\mathrm{OR}=6.04$ [95\% CI=3.17-11.49]) while those who had delivered three children in the presences of skilled birth attendants (SBAs) had the odds of delivering at home/outside hospital increased by 48.31 $(\mathrm{OR}=48.31$ [95\% CI=6.1-382.8]). This finding agrees with Navaneetham and Dharmalingam (2006) who reported that mothers who had previously delivered successfully with no complications tend to deliver at home.

Thus, it is worthwhile to note that, time when one visited health facility for pregnancy check-up $\left(P=1.80 \mathrm{e}^{-11}\right)$, reason for visiting health facility $(P=0.0001)$, type of health facility visited $\left(P<2.2 \mathrm{e}^{-16}\right)$, reason for visiting a particular type of health facility $\left(P<2.2 \mathrm{e}^{-16}\right)$, having delivered a baby at one time in the presence of skilled birth attendant $\left(P=7.58 \mathrm{e}^{-11}\right)$ and number of times delivered a baby in the presence of skilled birth attendant $\left(P=5.14 \mathrm{e}^{-14}\right)$ were significantly all related with the home/outside hospital delivery since their $p$ value $>\alpha=0.05$ (Table 6).

Moreover, it was also observed from this study findings that, the use of health services is influenced by the characteristics of the health delivery system for example, accessibility, quality, and cost of the services. However, even where there is a good supply of services, those services may not be fully used. Even under the same circumstances of availability, some women are more likely to use services than others. Therefore, a health delivery system is not the only factor that determines the level of use of health care services. Other factors such as social characteristics and structure influence the use of health care services. Several studies emphasize factors like cultural beliefs, sociodemographic characteristics, economic conditions, and physical and financial accessibility to be important determinants of the use of maternal health care services.

Table 6. Association between respondents' knowledge of skilled birth attendant and the place of delivery

\begin{tabular}{|c|c|c|c|c|}
\hline \multirow[t]{2}{*}{ Variables } & \multicolumn{4}{|c|}{ Place of delivery } \\
\hline & $\begin{array}{l}\text { Have at one } \\
\text { time delivered } \\
\text { at } \\
\text { home/outside } \\
\text { health facility }\end{array}$ & $\begin{array}{l}\text { Never at one } \\
\text { time } \\
\text { delivered at } \\
\text { home/outsid } \\
\text { e health } \\
\text { facility } \\
\end{array}$ & $\begin{array}{l}\text { Crude Odds Ratio } \\
\text { (95\% CI)p-value }\end{array}$ & $\begin{array}{l}\text { Chi- } \\
\text { square, } \\
\text { p-value }\end{array}$ \\
\hline $\begin{array}{l}\text { a). Went at one time to } \\
\text { Health facility (SBAs) for } \\
\text { Pregnancy check-up } \\
\text { (n=370) } \\
\text { Yes } \\
\text { No }\end{array}$ & $\begin{array}{l}275(74.3 \%) \\
0\end{array}$ & $\begin{array}{l}95(25.7 \%) \\
0\end{array}$ & NA & NA \\
\hline
\end{tabular}




\begin{tabular}{|c|c|c|c|c|}
\hline $\begin{array}{l}\text { b). Time when visited } \\
\text { Health Facility (SBAs) for } \\
\text { Pregnancy check-up } \\
\text { (n=370) } \\
\text { During Early Stages of } \\
\text { Pregnancy } \\
\text { At } 3 \text { months } \\
\text { At } 4 \text { months } \\
\text { At the Middle of Pregnancy } \\
\text { At } 5 \text { months } \\
\text { At } 6 \text { months } \\
\text { During Late Stages of } \\
\text { Pregnancy } \\
\text { When sick }\end{array}$ & $\begin{array}{l}74(79.6 \%) \\
5(100 \%) \\
11(100 \%) \\
95(80.5 \%) \\
22(37.9 \%) \\
7(43.8 \%) \\
43(89.6 \%) \\
18(85.7 \%)\end{array}$ & $\begin{array}{l}19(20.4 \%) \\
0 \\
0 \\
23(19.5 \%) \\
36(62.1 \%) \\
9(56.2 \%) \\
5(10.4 \%) \\
3(14.3 \%)\end{array}$ & $\begin{array}{l}1.06[0.54-2.09] 1 \\
0 \\
0 \\
\text { Reference } \\
6.8[3.4-13.6] 4.9 \mathrm{e}^{-} \\
08 \\
5.31[1.8-15.8] 0.003 \\
0.48[0.17-1.35] 0.24 \\
0.69[0.19-2.54] 0.8\end{array}$ & $\begin{array}{l}\text { Chi- } \\
\text { square= } \\
64.61 \\
\text { p-value = } \\
\mathbf{1 . 8 0 e ^ { - 1 1 }}\end{array}$ \\
\hline $\begin{array}{l}\text { c). Reason for visiting } \\
\text { Health Facility }(\mathbf{n}=\mathbf{3 7 0}) \\
\text { To avoid rejection by } \\
\text { nurses if pregnancy } \\
\text { developed complications } \\
\text { To check mother's and } \\
\text { baby's status } \\
\text { To get clinic card } \\
\text { Check-up/examination and } \\
\text { treatment } \\
\text { Medication } \\
\text { Check-up/examination and } \\
\text { medication } \\
\text { Medication and treatment } \\
\text { Check-up, treatment and } \\
\text { medication }\end{array}$ & $\begin{array}{l}31(86.1 \%) \\
98(62.8 \%) \\
11(100 \%) \\
23(65.7 \%) \\
55(84.6 \%) \\
42(87.5 \%) \\
14(87.5 \%) \\
2(100 \%)\end{array}$ & $\begin{array}{l}5(13.9 \%) \\
58(37.2 \%) \\
0 \\
12(34.3 \%) \\
10(15.4 \%) \\
6(12.5 \%) \\
2(12.5 \%) \\
0\end{array}$ & $\begin{array}{l}0.27[0.1-0.74] 0.01 \\
\text { Reference } \\
0 \\
0.88[0.41-1.9] 0.9 \\
0.3[0.15-0.65] 0.002 \\
0.24[0.1-0.6] 0.002 \\
0.24[0.05-1.1] 0.09 \\
0\end{array}$ & $\begin{array}{l}\text { Chi- } \\
\text { square= } \\
29.03 \\
\text { p-value }= \\
\text { 0.0001 }\end{array}$ \\
\hline $\begin{array}{l}\text { d). Type of health facility } \\
\text { visited }(\mathbf{n}=\mathbf{3 7 0}) \\
\text { Dispensary } \\
\text { Health Centre } \\
\text { Hospital }\end{array}$ & $\begin{array}{l}243(92.7 \%) \\
31(35.2 \%) \\
1(5 \%)\end{array}$ & $\begin{array}{l}19(7.3 \%) \\
57(64.8 \%) \\
19(95 \%)\end{array}$ & $\begin{array}{l}\text { Reference } \\
23.5[12.4- \\
44.6]<2.2 \mathrm{e}^{-16} \\
243[30.8- \\
1914.9]<2.2 \mathrm{e}^{-16} \\
\end{array}$ & $\begin{array}{l}\text { Chi- } \\
\text { square= } \\
167.46 \\
\text { p-value } \\
<2.2 e^{-16}\end{array}$ \\
\hline $\begin{array}{l}\text { e).Reason for visiting a } \\
\text { particular type of health } \\
\text { facility (n=370) } \\
\text { It's nearer } \\
\text { Has all services including } \\
\text { maternal services } \\
\text { Has all services and } \\
\text { maternal services are also } \\
\text { free } \\
\text { Offers good services } \\
\text { Offer free maternal services } \\
\text { Nearer and offer all } \\
\text { services } \\
\text { Nearer and also offer free } \\
\text { maternal services }\end{array}$ & $\begin{array}{l}246(86.9 \%) \\
14(26.9 \%) \\
0 \\
9(90 \%) \\
0 \\
0 \\
0\end{array}$ & $\begin{array}{l}37(13.1 \%) \\
38(73.1 \%) \\
12(100 \%) \\
1(10 \%) \\
6(100 \%) \\
6(100 \%) \\
1(100 \%)\end{array}$ & $\begin{array}{l}\text { Reference } \\
18.05[8.93-36.5] \\
<2.2 \mathrm{e}^{-16} \\
0 \\
0.74[0.09-6] 1 \\
0 \\
0 \\
0\end{array}$ & $\begin{array}{l}\text { Chi- } \\
\text { square }= \\
151.85 \\
\text { p-value } \\
<\mathbf{2 . 2 e ^ { - 1 6 }}\end{array}$ \\
\hline $\begin{array}{l}\text { f). Satisfied by the } \\
\text { services offered by the }\end{array}$ & $259(73.4 \%)$ & $94(26.6 \%)$ & Reference & Chi- \\
\hline
\end{tabular}




\begin{tabular}{|c|c|c|c|c|}
\hline $\begin{array}{l}\text { health facility visited } \\
(\mathbf{n}=\mathbf{3 7 0}) \\
\text { Yes } \\
\text { No }\end{array}$ & $16(94.1 \%)$ & $1(5.9 \%)$ & $0.17[0.02-1.32] 0.1$ & $\begin{array}{l}\text { square }= \\
2.65 \\
\text { p-value }= \\
0.1034\end{array}$ \\
\hline $\begin{array}{l}\text { e). Rating of the services } \\
\text { offered by the health } \\
\text { facility visited ( } \mathbf{n}=\mathbf{3 7 0} \text { ) } \\
\text { Good } \\
\text { Poor (didn't receive } \\
\text { nutritional advice) } \\
\text { Poor (took a lot of time) } \\
\text { Poor (harassed by health } \\
\text { staffs) }\end{array}$ & $\begin{array}{l}259(73.4 \%) \\
7(100 \%) \\
5(83.3 \%) \\
4(100 \%)\end{array}$ & $\begin{array}{l}94(26.6 \%) \\
0 \\
1(16.7 \%) \\
0\end{array}$ & $\begin{array}{l}\text { Reference } \\
0 \\
0.55[0.06-4.78] 0.9 \\
0\end{array}$ & $\begin{array}{l}\text { Chi- } \\
\text { square= } \\
4.22, \\
\text { p-value }= \\
0.2383\end{array}$ \\
\hline $\begin{array}{l}\text { f). Have delivered a baby } \\
\text { at one time in the } \\
\text { presence of skilled birth } \\
\text { attendant }(n=370) \\
\text { Yes } \\
\text { No }\end{array}$ & $\begin{array}{l}180(65.5 \%) \\
95(100 \%)\end{array}$ & $\begin{array}{l}95(34.5 \%) \\
0\end{array}$ & $\begin{array}{l}\text { Reference } \\
0\end{array}$ & $\begin{array}{l}\text { Chi- } \\
\text { square= } \\
42.36, \\
\text { p-value }= \\
\mathbf{7 . 5 8 e}^{-11}\end{array}$ \\
\hline $\begin{array}{l}\text { g). Number of times } \\
\text { delivered a baby in the } \\
\text { presence of skilled birth } \\
\text { attendant (n=275) } \\
1 \\
2 \\
3 \\
4 \\
5 \\
6 \\
7\end{array}$ & $\begin{array}{l}157(80.1 \%) \\
22(40 \%) \\
1(7.7 \%) \\
0 \\
0 \\
0 \\
0\end{array}$ & $\begin{array}{l}39(19.9 \%) \\
33(60 \%) \\
12(92.3 \%) \\
1(100 \%) \\
2(100 \%) \\
5(100 \%) \\
3(100 \%)\end{array}$ & $\begin{array}{l}\text { Reference } \\
6.04[3.17-11.49] \\
1.68 \mathrm{e}^{-08} \\
48.31[6.1-382.8] \\
2.81 \mathrm{e}^{-08} \\
0 \\
0 \\
0 \\
0\end{array}$ & 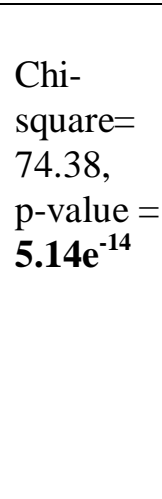 \\
\hline
\end{tabular}

\section{Conclusion}

The period of birth is critical in the life of both the mother and the baby. Ideally, it needs to be assisted in a competent manner by a skilled birth attendant (SBA) supported by an enabling environment (Indira et al., 2004). A measure of the proportion of deliveries assisted by skilled birth attendants is one of the indicators of progress towards achieving Millennium Development Goal (MDG) 5, which aims at improving maternal health (Wanjira et al., 2011).

Skilled birth attendance is the process by which an expectant woman is provided with adequate care during labour, delivery and postpartum period and requires both a skilled attendant and an enabling environment. It is noted that the higher the proportion of deliveries attended by skilled attendants in a country the lower the country's maternal mortality ratio (Sibley \& Snipe, 2006; Lawn et al., 2011; Utz et al., 2013).

Skilled birth attendant is important during pregnancy, at child birth as well as after delivery period. This study demonstrated that all of the 370 respondents who were recruited, had at one time gone to health facility to seek the services of skilled birth attendant for pregnancy check-up, giving a response rate for health facility utilization of $100 \%$. According to KDHS (KDHS, 2014) findings it was reported that $81.8 \%$ delivery in the city centres within Mombasa County were attended by skilled birth attendants (SBAs) as compared to $40 \%$ which were observed in some of the County's rural sub counties. The national record reported by the KHDSS (2014) for all births delivered under skilled professional stood at $43.1 \%$.

The main reason why most expectant mothers failed to attend the free maternal service currently being offered by the government was that health facilities were distantly far, fear of harassment by health staffs (nurses) and payment for unavailable items in most of the facilities (40\%). It can 
DOI: $10.21522 / \mathrm{TIJPH} .2013 .06 .03$. Art001

ISSN: $2520-3134$

therefore, be concluded that there is need to improve the quality of existing facility-based delivery services and to strengthen linkages between the expectant mothers and the health facilities so as to increase the number of health facility-based delivery. The relevant authority should put more emphasis on patient satisfaction as a way of attracting more patients to deliver in health facility.

\section{Acknowledgements}

This analysis is part of the first author's thesis to fulfil the requirement for a $\mathrm{PhD}$ in Public Health at the Texila American University Guyana. We thank the Ministry of Health at both the National Government and Mombasa County Government. Special thanks too to the 370 study participants for providing valuable information.

\section{References}

[1]. Bettina Utz, Ghazna Siddiqui, Adetoro Adegoke \& Nynke Van Den Broek (2013). Definitions and roles of a skilled birth attendant: a mapping exercise from four South-Asian countries. Acta Obstetricia et Gynecologica Scandinavica. 92: 1063-1069.

[2]. Fisher AA, Laing EJ, Stoeckel EJ, Townsend WJ (1998). Handbook for family planning operations research design. New York, NY, USA: Population Council; p.36.

[3]. Government of Kenya (GoK, 2012). Accelerating attainment of Health Goals: The First Kenya Health Sector Strategic and Investment Plan - KHSSP July 2012 - June 2018. Afya House, Nairobi.

[4]. Indira, N., Shaver, T., Clark, P.A, Cordero, D., \& Faillace, S. (2004). Entry into this World: Who Should Assist? Birth Attendants and Newborn Health.

[5]. John Njuguna, Njoroge Kamau and Charles Muruka (2017). Impact of free delivery policy on utilization of maternal health services in county referral hospitals in Kenya. BMC Health Services Research.17:429

[6]. KDHS. (2014). Kenya demographic and health survey: Key indicators, 1-76.

[7]. Lincetto O, Mothebesoane-anoh S, Gomez P, Munjanja S (2010). Antenatal Care: Opportunities for Africa's Newborns. New York: World Health Organization.

[8]. Lunan, B., Clements, Z, Mahony, S., \& Hope-Jones, D., (2010). Maternal health in Malawi: challenges and Success. Scotland Malawi Partnership.

[9]. Martin LT, McNamara MJ, Milot AS, Halle T, Hair EC (2007). The effects of father involvement during pregnancy on receipt of prenatal care and maternal smoking. Matern Child Health J;11(6):595-602.

[10]. MoHSW (2015). Tanzania Health Sector Strategic Plan 2015-2020 (HSSP IV). Vol. 2020.

[11]. Moore, M., Copeland, R., Chege, S., Pido, D. \& Griffiths, M. (2002). A behavior Change Approach to investigating factors influencing Women's use of Skilled Care in Homabay District, Kenya.

[12]. Mwewa D, Michelo C (2010). Factors associated with home deliveries in a low-income rural settingobservations from Nchelenge District Zambia. Med J Zambia. 37(4):234-9.

[13]. Navaneetham K, Dharmalingam A (2006). Utilization of maternal health care services in Southern India. Soc Sci Med. 55:1849-69.

[14]. Shiferaw, S., Spigt, M., Godefrooij, M., Melkamu, Y., \& Tekie, M. (2013). Why do women prefer home births in Ethiopia? BMC Pregnancy Childbirth, 13:2393-13-5.

[15]. Sibley, L., \& Snipe (2006). Transition to Skilled Birth Attendance, Is there a future role for trained TBAs. Journal Health Pop and Nutrition. 24(4): 472-478.

[16]. Tawiah E (2007). Maternal health in five Sub-Saharan African countries. Poster Presentation at the Fifth African Population Conference. In: (2007); 10-14 December, Arusha Interntional conference center, Arusha.

[17]. Thaddeus S, Maine D (1994). "Too far to walk: maternal mortality in context". Social Science and Medicine. 38(8):1110.

[18]. Titaley CR, Hunter CL, Dibley MJ, Heywood P (2010). Why do some women still prefer traditional birth attendants and home delivery? A qualitative study on delivery care services in West Java Province, Indonesia. BMC Pregnancy Childbirth. 10:43.

[19]. Utz Bettina, Ghazna Siddiqui, Adetoro Adegoke \& Nynke Van Den Broek (2013). Definitions and roles of a skilled birth attendant: a mapping exercise from four South-Asian countries. Acta Obstetricia et Gynecologica Scandinavica. 92: 1063-1069. 
[20]. Vieira, C., Portela, A., Miller, T., Coast, E., Leone, T., \& Marston, C. (2012). Increasing the use of skilled health personnel where traditional birth attendants were providers of childbirth care: A systematic review. PLoS ONE. 7(10), e47946.

[21]. Wanjira, C., Mwangi, M., Mathenge, E., Mbugua, G. \& Ng ang a, Z. (2011). Delivery Practices and Associated factors among Mothers Seeking Child welfare Services in selected Health Facilities in Nyandarua South District, Kenya. BMC, Public Health.

[22]. World Health Organization (2018). Skilled attendants at birth. Global Health Observatory (GHO) data; Maternal and reproductive health.

[23]. World Health Organization (2012). Neonatal and Child Health Profile.

[24]. World Health Organisation (2010). Classifying Health Workers. Geneva.

[25]. WHO (2004). Road Map for Accelerating the Attainment of the MDGs Related to Maternal and Newborn Health in Africa. African Regional Reproductive Health Task Force Meeting. In. Harare.

[26]. World Health Organization (1992). Traditional Birth Attendants: a joint WHO/UNFPA/UNICEF statement. Geneva. 